\title{
A survey of United States dairy hoof care professionals on costs associated with treatment of foot disorders
}

\author{
K. A. Dolecheck, ${ }^{* 1}$ R. M. Dwyer, ${ }^{*}$ M. W. Overton, $†$ and J. M. Bewleył \\ *Department of Animal and Food Sciences, University of Kentucky, Lexington 40546 \\ †Elanco Animal Health, 2500 Innovation Way, Greenfield, IN 46140 \\ $\ddagger$ CowFocused Housing, 100 Killarney Drive, Bardstown, KY 40004
}

\section{ABSTRACT}

The objective of this study was to collect information regarding hoof care professionals' billing practices and to gather their opinions about foot disorders and the value of their prevention. Responses were gathered from veterinarians $(\mathrm{n}=18)$ and hoof trimmers $(\mathrm{n}=$ 116) through both online and paper survey platforms. Because of the limited number of respondents, veterinarian responses were not further analyzed. Of the 6 foot disorders included in the survey, the treatment cost per case was greatest for toe ulcers (mean \pm standard deviation; $\$ 20.2 \pm 8.5)$, sole ulcers $(\$ 19.7 \pm 8.6)$, white line disease $(\$ 19.5 \pm 8.1)$, and thin soles $(\$ 18.1 \pm 8.1)$, and least for infectious disorders (foot rot and digital dermatitis; $\$ 8.0 \pm 7.6$ and $\$ 7.5 \pm 9.6$, respectively). Of the disorders, digital dermatitis represented most of the foot disorder cases treated by respondents over the past year $(43.9 \pm 20.4 \%)$, whereas toe ulcers and thin soles represented the least $(5.3 \pm 4.1$ and $5.3 \pm 5.7 \%$, respectively). Respondents that served mostly large herds (>500 lactating cows) reported a lower prevalence of digital dermatitis $(31.6 \pm 4.2$ vs. $44.4 \pm 3.4$ and 46.7 $\pm 3.2 \%$ in small and medium herds, respectively) and a higher prevalence of sole ulcers $(23.1 \pm 3.0$ vs. 13.4 \pm 2.4 and $13.3 \pm 2.3 \%$ in small and medium herds, respectively). Region of the United States (Northeast, Midwest, or other) also influenced foot disorder prevalence; respondents from the Northeast reported more sole ulcers than respondents from other regions (22.1 \pm 2.3 vs. $12.4 \pm 3.3 \%$ ). When respondents were asked which disorder was associated with the greatest total cost per case to the producer (treatment and labor costs plus the reduction in milk yield, reduced reproductive performance, and so on), hoof trimmers ranked digital dermatitis as having the greatest total cost per case and thin soles as having the least total cost per case.

Received March 8, 2018

Accepted May 22, 2018.

${ }^{1}$ Corresponding author: dolecheck.1@osu.edu
Finally, respondents indicated that the most important benefits of reducing foot disorders were enhanced animal welfare and increased milk production, whereas the least important benefit was reduced veterinary and hoof trimmer fees. Results from this survey can be used to improve the accuracy of foot disorder cost estimates and contribute to better decision-making regarding both foot disorder treatment and prevention.

Key words: lameness, hoof health, disease treatment costs, animal health economics

\section{INTRODUCTION}

Lameness is a clinical sign, expressed as irregular gait or posture, associated with any painful disorder of the locomotor system (Van Nuffel et al., 2015). In dairy cattle, the main cause of lameness is foot disorders (Van Nuffel et al., 2015). The most common foot disorders found in United States dairy herds are digital dermatitis, sole ulcer, white line disease, foot rot, toe ulcer, and thin sole (Bicalho et al., 2007; Sanders et al., 2009; DeFrain et al., 2013).

Each case of a foot disorder results in an expense for the dairy producer. Foot disorder expenses include direct expenditures in the form of treatment (i.e., outside labor, producer labor, and therapeutics) and indirect losses (i.e., nonsaleable milk, reduced milk production, reduced reproductive performance, increased risk of culling and death, increased risk of foot disorder recurrence, increased risk of other diseases, and reduced animal welfare; Dolecheck and Bewley, 2018). The total cost per case of a foot disorder depends on the type of disorder and other cow and farm specific factors (e.g., cow age, DIM at occurrence, market prices). Dolecheck and Bewley (2018) summarized previous studies that have estimated the cost of non-disorder-specific lameness, as well as specific foot disorders. Most recently, Charfeddine and Pérez-Cabal (2017) estimated the cost per case of sole ulcer, white line disease, and digital dermatitis in Spanish dairy herds, finding that sole ulcers were the most expensive ( $\$ 232$ to $\$ 622 /$ case) 
whereas digital dermatitis was the least expensive $(\$ 53$ to $\$ 402 /$ case).

One limitation of current foot disorder cost estimates is that many of the expenditures and losses that contribute to the cost per case are not easily defined. For example, treatment expenditures are often based on the author's opinion (Guard, 2008; Bruijnis et al., 2010) or outdated values (Cha et al., 2010). In reality, these costs depend on the type of foot disorder, the severity of the condition, the treatment used, and the person treating the case (i.e., producer, hoof trimmer, or veterinarian). The best estimate of these costs would come from those that charge the producer for them (i.e., hoof trimmers and veterinarians). Recently, Charfeddine and Pérez-Cabal (2017) conducted a survey of Spanish hoof trimmers to define the costs charged to producers to treat a case of sole ulcer, white line disease, or digital dermatitis; however, no similar estimates are available for the United States dairy industry.

Our study aimed to collect and summarize information on foot disorder treatment costs charged by hoof trimmers and veterinarians to dairy producers. The resulting values could be used to improve foot disorder cost estimates, therefore improving decisions about foot disorder treatment and prevention. Additional insight was provided into hoof trimmers' general billing practices and views on the prevalence and total cost of different foot disorders and the value of their prevention.

\section{MATERIALS AND METHODS}

\section{Survey Development}

A survey was drafted with the goal of defining treatment costs for foot disorders as charged to producers by hoof trimmers and veterinarians. The drafted survey was reviewed by industry veterinarians $(\mathrm{n}=2)$, academic veterinarians $(\mathrm{n}=5)$, academic professionals $(\mathrm{n}$ $=7$ ), and animal science graduate students $(\mathrm{n}=10)$ to collect feedback on content and organization. Based on collected feedback, revisions were made before the survey was sent to potential respondents. The final survey questions are included in Appendix Figure A1. The revised survey was also reviewed by the University of Kentucky Institutional Review Board and found exempt from human subject protection regulations as described in the US Department of Health and Human Services Federal Policy for Protection of Human Subjects 45CFR46.101(b).

Demographic information elicited by the survey included profession (veterinarian, hoof trimmer, or other), the location of practice (country or states served, if within the United States), herd sizes served, and the mean number of dairy cows trimmed per week (broken out into preventive and treatment trimmings). Respondents selecting other for their profession were removed from the survey results because they were outside of the target audience. General practice questions were formulated to evaluate the rate charged by hoof trimmers and veterinarians to come to a farm and conduct either preventive or treatment trimmings. These questions included (1) asking respondents if they charged a visit, daily, or set-up fee and, if so, how much; (2) the on-farm rate $(\$ / \mathrm{h}$ or $\$ /$ cow $)$ charged for preventive trimming; and (3) the mean number of cows trimmed per hour.

Condition-specific foot disorder questions focused on 6 disorders: digital dermatitis, foot rot, sole ulcer, thin sole, toe ulcer, and white line disease. These disorders were chosen based on their expected prevalence and feedback from those who reviewed the first version of the survey. All disorders were defined within the survey according to industry standards (Zinpro, 2014; Appendix Figure A2). Condition-specific questions included the total amount charged to the producer for treatment of each disorder along with the percent of the total cost attributed to labor and the percent of the total cost attributed to supplies. Additionally, respondents were asked to estimate the amount of time spent to treat a case of each disorder, the percent of lameness cases treated in the past year attributed to each disorder, and milk withhold recommendations following treatment. Retrospectively, the question about milk withhold recommendations was removed from the study results because of US regulations restricting hoof trimmers from prescribing antibiotics.

Finally, respondents were asked to answer 2 rank order questions. First, they were asked to rank the 6 foot disorders based on their opinion of the total cost per case to the producer (treatment and labor costs plus the reduction in milk yield, reduced reproductive performance, and so on) from most expensive (1) to least expensive (6). Second, they were asked to rank the importance to producers of 8 potential benefits (identified by the authors) of reducing dairy cow lameness from most important (1) to least important (8). The potential benefits included decreased incidence of other diseases (not lameness), enhanced animal welfare, increased milk production, increased reproductive performance, increased cow longevity, reduced drug and supply costs, reduced producer labor costs, and reduced veterinary and hoof trimmer fees.

\section{Survey Distribution}

The target audience for the survey was veterinarians and hoof trimmers; therefore, the American Association of Bovine Practitioners (AABP) and the Hoof Trim- 
mers Association (HTA) were identified as potential respondent sources. Based on the response rates from $\mathrm{AABP}$ and HTA members to a previous lameness survey (Kleinhenz et al., 2014), the decision was made to create an online version of the survey for AABP members and a paper version of the survey for HTA members.

The online survey was created using Qualtrics (Qualtrics Research Suite, Provo, UT). We identified that the best way to distribute the online survey to AABP members would be through their member e-mail listserv ( $\mathrm{n} \approx 2,000$ recipients). A link to the survey was first sent to the AABP listserv on June 12, 2017. Follow-up emails were sent to the AABP listserv $1 \mathrm{wk}$ and again $4 \mathrm{wk}$ after the original email solicitation to remind potential respondents to complete the survey. The final email to the AABP listserv, sent on August 1,2017 , indicated that the survey would be closing on August 15, 2017. All emails sent to AABP members and the online survey itself included instructions for accessing and returning (via mail at their own expense) a downloadable paper version of the survey in case that was the respondent's preference. All online surveys submitted by and paper surveys received by August 31, 2017 , were included in the analysis.

Hoof trimmers identified by the HTA $(\mathrm{n}=548)$ were mailed a paper survey with identical questions as the online survey on June 12, 2017, using a third-party mailing company selected by the HTA. The paper survey included prepaid envelopes to return the survey to the University of Kentucky. The paper survey also included instructions to access the online version of the survey in case that was the respondent's preference. One week after the first paper survey mailing, a followup postcard was sent to all original recipients to remind them to return the survey. A difference in postage class resulted in the reminder postcards arriving before the originally mailed paper survey. Because of this, the second and final mailing of the paper survey (only sent to nonrespondents) was delayed until 5 wk after the original mailing (July 17, 2017). Nonrespondents were identified by labeling the originally mailed surveys with a number that corresponded to a recipient. The list of recipients was not referenced after the final mailing. All paper surveys received by August 31, 2017, were included in the analysis.

At survey closure, 83 people had started the online survey and 16 completed the entire online survey (completion rate $=19 \% ; \mathrm{n}=12$ veterinarians and $\mathrm{n}$ $=4$ hoof trimmers). One hundred twenty-three paper surveys were returned, and only 1 was from a veterinarian. Therefore, we obtained a $22 \%$ response rate from the targeted mailing list. Nine paper survey respondents indicated that they were retired, 1 respondent indicated that they only trimmed beef cattle, and 1 other indicated that they only trimmed for their own herd; these 11 surveys were removed from the data set.

\section{Statistical Analysis}

Responses from paper surveys were manually entered into the online survey to standardize data from both sources. When respondents reported a range for any answer (e.g., indicated that they trimmed 10 to 15 cows per hour), the mean of the range was calculated for further analysis (e.g., 12.5 cows per hour). For questions where answers were supposed to add up to $100 \%$, (i.e., the percent of each type of foot disorder treated and the percent of the total cost attributed to labor and supplies), if the total was not $100 \%$ the answers were standardized to total $100 \%$. For rank order questions, if 2 or more options were ranked the same, the tied rankings were removed from the data set $(\mathrm{n}=4$ for the rank order question about the total cost per case of disorders and $\mathrm{n}=5$ for the rank order question about the importance of potential benefits of reducing lameness). Finally, any unanswered questions were removed from the data set.

Respondents were categorized by profession (veterinarian or hoof trimmer), region of practice, herd sizes served, and trimming frequency. The region of practice was defined based on a respondent's answer to which states they served in the United States. The region classifications included Midwest (states represented included Iowa, Illinois, Indiana, Kansas, Michigan, Minnesota, North Dakota, Nebraska, Ohio, South Dakota, and Wisconsin), Northeast (states represented included Connecticut, Massachusetts, Maryland, Maine, New Hampshire, New York, Pennsylvania, Rhodes Island, and Vermont), Southeast (states represented included Alabama, Arkansas, Florida, Georgia, Kentucky, Missouri, Mississippi, Tennessee, and Virginia), Southwest (states represented included New Mexico and Texas), and West (states represented included Colorado, Idaho, Montana, Oregon, and Washington). If the respondent indicated they served herds in more than 1 region, their region was defined based on the category representing most of the listed states. Eighty-two percent of respondents were from either the Midwest or the Northeast; therefore, the remaining regions were grouped into an "other" region category. Only 3 usable responses were from outside the United States; these responses were removed from the data set because of the inability to distinguish which currency answers were given in.

Herd size served was based on each respondent's answer to the question, "Estimate the number of farms you perform preventive or corrective trimming for each year that would fall under each category: small herds 
$(<100$ lactating cows), medium herds (between 100 and 500 lactating cows), and large herds (>500 lactating cows)." Respondents were placed into 1 of 3 categories based on which size herds represented most of their clientele. A respondent with most of their clientele classified as small herds was categorized as a small herd size served, a respondent with most of their clientele classified as medium herds was categorized as a medium herd size served, and a respondent with most of their clientele classified as large herds was categorized as a large herd size served. In cases where the respondent served the same number of herds in 2 categories, preference was given to the extreme value (i.e., if the same number of small and medium-sized herds were served, the respondent was classified as a small herd size served, and if the same number of medium and large herds were served, the respondent was classified as a large herd size served; in no cases were the same number of small and large sized herds served).

Trimming frequency was based on the response to the question, "On average, how many dairy cows do you conduct preventive trimming for weekly (i.e., routine trimming)?" Tertiles were calculated from the responses used in linear regression analysis and were used to classify trimming frequency as either low $(\leq 150$ trims per week), medium (between 150 and 250 trims per week), or high ( $\geq 250$ trims per week).

Statistical analyses were conducted using SAS Version 9.4 (SAS Institute Inc., Cary, NC). For both online and paper surveys, provided answers were included in the descriptive statistics even if a respondent did not finish the survey (22 and $78 \%$ completion rate for online and paper surveys, respectively). The MEANS procedure was used to summarize how many cows were trimmed per hour when conducting preventive trims, the rate charged for preventive trimming, the percent of lameness treatments attributed to each foot disorder, the time spent treating each foot disorder, the total cost of treatment per case of each foot disorder, the percent of the total cost of treatment of each foot disorder attributed to labor, and the percent of the total cost of treatment of each foot disorder attributed to supplies. The FREQ procedure was used to summarize if an extra fee was charged (yes or no) and the frequency of ranking for both rank order questions.

Because very few useable responses were received from veterinarians (18 surveys included enough information to be used in at least 1 mean calculation), only hoof trimmer responses were analyzed for statistical difference by demographics. The GLM procedure of SAS was used to analyze the effects of region, herd size served, and trimming frequency on the preventive trimming rate, the number of cows trimmed per hour, the percent of treated lameness cases attributed to each foot disorder, the amount of time spent treating each foot disorder, the total cost charged to producers for treatment of each foot disorder, the percent of the total cost of treatment for each foot disorder attributed to labor, and the percent of the total cost of treatment for each foot disorder attributed to supplies. The effects were calculated as

$$
\begin{gathered}
y_{i j k l}=\mu+\text { Region }_{i}+\text { Herd }_{\text {Size }} \\
+ \text { Trimming Frequency } \\
k
\end{gathered}
$$

where $y$ is the outcome variable of interest for the $l$ th respondent classified in the $k$ th trimming frequency category, the $j$ th herd size served category, and the $i$ th region; $\mu$ is the intercept; for region, $i$ is Midwest, Northeast, or other; for herd size, $j$ is small, medium, or large; for trimming frequency, $k$ is low, medium, or high; and $e_{i j k l}$ is residual error. For all models, differences were considered significant when $P<0.05$ and all effects were retained regardless of significance.

\section{RESULTS AND DISCUSSION}

The objective of our study was to gain insight into foot disorder treatment costs charged to dairy producers by hoof trimmers and veterinarians. Table 1 summarizes the distribution of respondents used in at least 1 descriptive statistic calculation by profession, survey type returned, region of practice, herd size served, and trimming frequency. The survey distribution methods used in our study (i.e., online surveys for veterinarians and mailed surveys for hoof trimmers) were based on results from Kleinhenz et al. (2014), who surveyed the same population. Different from Kleinhenz et al. (2014), we received very few completed AABP responses to our online survey. The low completion rate of online surveys could indicate that veterinarians who started the survey deemed the topic inapplicable to them. To support the idea that the veterinarian respondents were less involved in foot disorder treatment than the hoof trimmer respondents, all veterinary respondents to the survey were categorized in the low trimming frequency group (Table 1). Additionally, 1 veterinary respondent stated, "I rarely get asked to work on lame cows." In agreement, Adams et al. (2017) reported that $77 \%$ of United States dairy farms used a professional hoof trimmer for hoof health services compared with only $16 \%$ using a veterinarian or on-farm staff. One factor that might contribute to lower trimming frequencies among veterinarians is that hoof trimmers conduct more preventive trimming and are more likely to see both lame and nonlame cows, whereas veterinarians are more likely to only see selected cows with severe foot 
Table 1. Distribution of respondents to a survey ${ }^{1}$ about dairy foot disorder treatment costs by profession, survey type, region, herd size served, and trimming frequency

\begin{tabular}{|c|c|c|c|}
\hline \multirow[b]{2}{*}{ Category } & \multicolumn{2}{|c|}{ Profession } & \multirow[b]{2}{*}{ Total } \\
\hline & Veterinarian & $\begin{array}{c}\text { Hoof } \\
\text { trimmer }\end{array}$ & \\
\hline \multicolumn{4}{|l|}{ Survey type } \\
\hline Online & 17 & 5 & 22 \\
\hline Paper & 1 & 111 & 112 \\
\hline \multicolumn{4}{|l|}{ Region $^{2}$} \\
\hline Midwest & 11 & 55 & 66 \\
\hline Northeast & 3 & 41 & 44 \\
\hline Other & 4 & 20 & 24 \\
\hline \multicolumn{4}{|l|}{ Herd size served ${ }^{3}$} \\
\hline Small $(<100$ cows $)$ & 7 & 45 & 52 \\
\hline Medium (100 to 500 cows) & 7 & 42 & 49 \\
\hline Large (>500 cows $)$ & 0 & 25 & 25 \\
\hline \multicolumn{4}{|l|}{ Trimming frequency ${ }^{4}$} \\
\hline Low $(<150$ cows/wk $)$ & 18 & 32 & 50 \\
\hline Medium (150 to 250 cows/wk) & 0 & 41 & 41 \\
\hline High $(>250$ cows $/ w k)$ & 0 & 42 & 42 \\
\hline Total & 18 & 116 & \\
\hline
\end{tabular}

${ }^{1}$ An online version of the survey was sent to the American Association of Bovine Practitioners listserv $(\mathrm{n} \approx 2,000$ members) and a paper version of the survey was mailed to 548 hoof trimmers identified by the Hoof Trimmers Association; responses with enough data to include in 1 mean calculation are included in the table.

${ }^{2}$ Midwest states represented included IA, IL, IN, KS, MI, MN, ND, NE, OH, SD, and WI; Northeast states represented included CT, MA, MD, ME, NH, NY, PA, RI, and VT; Other states represented included AL, AR, FL, GA, KY, MO, MS, TN, VA, NM, TX, CO, ID, MT, OR, and WA.

${ }^{3}$ Herd size served was categorized based on whether the respondent's clients were mostly small herds ( $<100$ lactating cows), medium herds (between 100 and 500 lactating cows), or large herds ( $>500$ lactating cows). Eight respondents did not provide sufficient information to classify them according to herd size served but were still included in descriptive statistics.

${ }^{4}$ Trimming frequency was categorized based on the calculated tertiles of responses used in linear regression analysis; 1 respondent did not provide sufficient information to classify hoof trimming frequency but was still included in descriptive statistics.

disorders (Kleinhenz et al., 2014). Still, a limitation of the current study is that the received responses, especially from veterinarians, may not be entirely representative of the target population because of nonresponse bias. Because of this, veterinarian response summary statistics are only included in the Appendix (Tables $\mathrm{A} 1, \mathrm{~A} 2$, and $\mathrm{A} 3$ ). Interpretation of veterinarian responses should be conducted carefully, keeping in mind the limited response rate.

\section{General Practice Questions}

On average, hoof trimmers reported trimming 10.0 \pm 5.0 cows per hour $(\mathrm{n}=116)$. The number of cows trimmed per hour differed by trimming frequency, with low and medium frequency trimmers trimming fewer cows per hour than high frequency trimmers $(7.66 \pm$
$0.66,9.34 \pm 0.79$, and $13.70 \pm 0.66 \mathrm{cows} / \mathrm{h}$, respectively; $\mathrm{n}=111 ; P<0.01)$. This could be because trimmers who trim more frequently are better practiced or have better equipment than trimmers that trim less frequently. Alternatively, trimmers who trim more frequently may have regular clients, making trimming visits quicker (because the cows' hooves are in better shape) than a farm that is not visited by a hoof trimmer regularly.

Ninety-nine percent $(\mathrm{n}=114)$ of hoof trimmer respondents billed per cow, rarely charging an extra fee (visit, daily, or setup) of any kind (only $12 \%$ of respondents, mean $\pm \mathrm{SD}=\$ 87.9 \pm 133.4, \mathrm{n}=14)$. The mean $( \pm \mathrm{SD})$ rate charged by hoof trimmers was $\$ 12.55 \pm$ $2.38 /$ cow $(\mathrm{n}=113)$. Trimming rate $(\$ / \mathrm{cow})$ differed by region and herd size served. Hoof trimmers from the Midwest charged a greater fee $(\$ 13.21 \pm 0.31 /$ cow $)$ than hoof trimmers from either the Northeast $(\$ 11.73$ $\pm 0.33 / \mathrm{cow})$ or other regions in the United States $(\$ 10.89 \pm 0.47 /$ cow; $\mathrm{n}=108 ; P<0.01)$. A large portion of dairy farms in the United States are located in the Midwest (USDA, 2017), potentially contributing to a greater demand for hoof trimmers and the ability to charge an increased fee. Hoof trimmers serving mostly large herds charged a reduced fee $(\$ 11.10 \pm 0.43)$ compared with those serving mostly medium-sized herds $(\$ 12.54 \pm 0.33 /$ cow, $P=0.04)$. Neither was different from hoof trimmers serving mostly small herds $(\$ 12.19$ $\pm 0.35 / \mathrm{cow})$. The effect of herd size on fees charged by hoof trimmers could be attributed to economies of scale, where large farms would be charged less because the fixed costs of hoof trimming (e.g., travel expenses) could be spread over more cows. Although interactions were not tested in the model, it was noted that the ranking of rates charged to different herd sizes differed numerically by region with hoof trimmers in the Midwest charging the most to large herds, hoof trimmers in the Northeast charging the most to medium herds, and hoof trimmers in other regions charging the most to small herds.

\section{Specific Foot Disorders}

Prevalence of Foot Disorders. Among treated foot disorder cases over the past year, respondents estimated that digital dermatitis was most prevalent, followed by sole ulcers, white line disease, other lameness, foot rot, toe ulcers, and thin soles, respectively (Table 2). Very few studies identifying specific lesions have been conducted in the United States, making an estimate of actual foot disorder prevalence or incidence difficult. Bicalho et al. (2007) found in 459 cows on a New York dairy that the most common foot disorders were sole ulcers $(52 \%)$, digital dermatitis (20\%), 
white line disease $(15 \%)$, other lameness $(10 \%)$, toe ulcers $(3 \%)$, and foot rot (1\%). Similar to Bicalho et al. (2007), other studies have identified sole ulcers as the most common foot disorder causing lameness in dairy cows, but rarely do studies include identification of toe ulcers or thin soles (Amory et al., 2008; Gernand et al., 2012). Sanders et al. (2009) did record both thin soles and toe ulcers in a Florida herd of 4,915 cows, finding that $38 \%$ of lameness cases were attributed to other lameness (including digital dermatitis, foot rot, heel ulcers, leg injuries, sole punctures, and others), $20 \%$ to thin sole induced toe ulcers, $16 \%$ to sole ulcers, $13 \%$ to thin soles, $10 \%$ to white line disease, and $2 \%$ to toe ulcers.

Inconsistent with the above previous research, hoof trimmer respondents to our survey reported the percentage of treated cases attributed to digital dermatitis as much greater than the cases attributed to sole ulcers (44 vs. 16\%). One factor that might contribute to this is that hoof trimmers often conduct preventive trimming and are likely to see both lame and nonlame cows, thereby observing both mild and severe conditions. Additionally, the types and prevalence of foot disorders present in a herd depends on both management and the environment (Cook and Nordlund, 2009). Therefore, variation among herds is expected and likely contributed to the variation in reported prevalence of foot disorders seen in our study. DeFrain et al. (2013), in an evaluation of 8 confinement dairies throughout the United States, found that $47.7 \%$ of lameness events were caused by digital dermatitis and $21.1 \%$ by sole ulcers, which would be in closer agreement to the findings in our study. Regardless, the viewpoint of the surveyed hoof trimmers likely does not represent the true prevalence of different foot disorders, because they do not always examine every lame cow and the respondents only represented a portion of the total population of dairy hoof trimmers.

Region, herd size served, and trimming frequency did not influence the percent of treatments over the past 12 mo classified as foot rot, thin soles, toe ulcers, white line disease, or other lameness $(P>0.05)$. The percent of digital dermatitis was influenced by herd size served $(P=0.02, \mathrm{n}=107)$, where hoof trimmers serving mostly large herds reported less digital dermatitis $(31.6 \pm 4.2 \%)$ than hoof trimmers serving mostly small- or medium-sized herds $(44.4 \pm 3.4$ and $46.7 \pm$ $3.2 \%$, respectively). One possible explanation for this observation is that large farms may have protocols and consistent labor available to prioritize footbath use. However, the exact reason for this observation cannot be extrapolated from the data available in our study. The percent of sole ulcers reported was influenced by region and herd size served $(P=0.03$ and $P=0.03$,
Table 2. Hoof trimmer responses to a survey regarding dairy foot disorder prevalence, time to treat, treatment costs, and the percentage of treatment costs attributed to labor or supplies

\begin{tabular}{|c|c|c|}
\hline Foot disorder & $\begin{array}{l}\text { Number of } \\
\text { responses }\end{array}$ & $\begin{array}{c}\text { Response } \\
(\text { mean } \pm \mathrm{SD})\end{array}$ \\
\hline \multicolumn{3}{|l|}{ Digital dermatitis } \\
\hline$\%$ of all foot disorders & 112 & $43.9 \pm 20.4^{1}$ \\
\hline Time to treat $(\min )$ & 113 & $2.2 \pm 1.9^{2}$ \\
\hline Total charged (\$/case) & 98 & $7.5 \pm 9.6$ \\
\hline$\%$ attributed to labor & 92 & $65.1 \pm 21.8$ \\
\hline$\%$ attributed to supplies & 92 & $34.9 \pm 21.8$ \\
\hline \multicolumn{3}{|l|}{ Foot rot } \\
\hline$\%$ of all foot disorders & 112 & $6.5 \pm 7.0$ \\
\hline Time to treat (min) & 111 & $3.7 \pm 2.7$ \\
\hline Total charged (\$/case) & 90 & $8.0 \pm 7.6$ \\
\hline$\%$ attributed to labor & 85 & $66.0 \pm 21.8^{3}$ \\
\hline$\%$ attributed to supplies & 85 & $32.8 \pm 20.8$ \\
\hline \multicolumn{3}{|l|}{ Sole ulcer } \\
\hline$\%$ of all foot disorders & 112 & $15.9 \pm 14.2^{1,3}$ \\
\hline Time to treat (min) & 114 & $6.2 \pm 3.5$ \\
\hline Total charged (\$/case) & 95 & $19.7 \pm 8.6$ \\
\hline$\%$ attributed to labor & 90 & $58.8 \pm 19.8$ \\
\hline$\%$ attributed to supplies & 90 & $41.2 \pm 19.8$ \\
\hline \multicolumn{3}{|l|}{ Thin sole } \\
\hline$\%$ of all foot disorders & 112 & $5.3 \pm 5.7$ \\
\hline Time to treat $(\min )$ & 107 & $5.1 \pm 3.3$ \\
\hline Total charged ( $\$ /$ case $)$ & 89 & $18.1 \pm 8.1$ \\
\hline$\%$ attributed to labor & 82 & $56.7 \pm 20.7$ \\
\hline$\%$ attributed to supplies & 82 & $43.3 \pm 20.7$ \\
\hline \multicolumn{3}{|l|}{ Toe ulcer } \\
\hline$\%$ of all foot disorders & 112 & $5.3 \pm 4.1$ \\
\hline Time to treat (min) & 111 & $7.1 \pm 3.6$ \\
\hline Total charged ( $\$ /$ case) & 96 & $20.2 \pm 8.5$ \\
\hline$\%$ attributed to labor & 91 & $57.5 \pm 20.5$ \\
\hline$\%$ attributed to supplies & 91 & $42.5 \pm 20.5$ \\
\hline \multicolumn{3}{|l|}{ White line disease } \\
\hline$\%$ of all foot disorders & 112 & $14.2 \pm 10.2$ \\
\hline Time to treat $(\min )$ & 113 & $6.5 \pm 3.1$ \\
\hline Total charged (\$/case) & 96 & $19.5 \pm 8.1$ \\
\hline$\%$ attributed to labor & 90 & $57.9 \pm 21.2$ \\
\hline$\%$ attributed to supplies & 90 & $42.1 \pm 21.2$ \\
\hline \multicolumn{3}{|l|}{ Other lameness } \\
\hline$\%$ of all foot disorders & 112 & $8.9 \pm 9.3$ \\
\hline
\end{tabular}

${ }^{1}$ Indicates a statistical difference between hoof trimmers by herd size served (small, medium, or large; $P<0.05$ ); further details included in the text.

${ }^{2}$ Indicates a statistical difference between hoof trimmers by trimming frequency (low, medium, or high; $P<0.05$ ); further details in the text.

${ }^{3}$ Indicates a statistical difference between hoof trimmers by region (Midwest, Northeast, or other region of the United States; $P<0.05$ ); further details included in the text.

respectively; $\mathrm{n}=107)$. Respondents from the Northeast reported more sole ulcers $(22.1 \pm 2.3 \%)$ than respondents from other regions in the United States (12.4 \pm $3.3 \%)$; neither differed from Midwestern respondents $(15.2 \pm 2.1 \%)$. It is possible that differences in style and age of housing contributed to these reported differences, but an exact reason for this observation is not clear. Respondents serving mostly large herds reported more sole ulcers $(23.1 \pm 3.0 \%)$ than respondents serving either medium-sized herds $(13.3 \pm 2.3 \%)$ or small-sized herds $(13.4 \pm 2.4 \%)$. This could be because large herds 
from the Midwest and Northeastern regions (most respondents) are more likely to house cows on concrete (NAHMS, 2014), which is a risk factor for sole ulcer development (Zinpro, 2014).

Treatment Time. Among all respondents, the mean time to treat a case of lameness was longest for toe ulcers, followed by white line disease, sole ulcers, thin soles, foot rot, and digital dermatitis (Table 2). Conditions requiring more remodeling of the foot, such as ulcers and white line disease (Andrews et al., 2008), required more time to treat. Region, herd size served, and trimming frequency did not influence the time required to treat foot rot, sole ulcers, thin soles, toe ulcers, or white line disease $(P>0.05)$. The time to treat digital dermatitis differed by trimming frequency, where hoof trimmers classified as high trimming frequency spent less time treating digital dermatitis $(1.6 \pm 0.3 \mathrm{~min})$ than those with a low trimming frequency $(3.0 \pm 0.3$ min; $P<0.01, \mathrm{n}=108)$. Hoof trimmers classified as medium trimming frequency fell in between the 2 extremes $(2.1 \pm 0.3 \mathrm{~min})$.

Cost of Treatment Per Case. The mean total treatment costs per case of each foot disorder was greatest for toe ulcers, followed by sole ulcers, white line disease, thin sole, foot rot, and digital dermatitis (Table 2). Previous studies focused on veterinarian and hoof trimmer opinions about foot disorder treatment costs are limited. Similar to our findings, Charfeddine and Pérez-Cabal (2017), in a survey of Spanish hoof trimmers, found that the cost to treat sole ulcers and white line disease were similar to each other, with the treatment of digital dermatitis being less. We observed that many of the respondents indicated that they charged equal amounts for the 2 infectious disorders (digital dermatitis and foot rot) and identical, but larger, amounts for noninfectious disorders (sole ulcers, white line disease, thin soles, and toe ulcers). This observation could be because similar supplies would be used to treat infectious (wrap) and noninfectious (block) foot disorders. The hoof trimmer reported cost of treatment per case did not differ by region, herd size served, or trimming frequency for any of the foot disorders $(P>0.05)$.

Treatment Costs Attributed to Labor Versus Supplies. The percent of the total cost of treatment attributed to either labor or supplies by foot disorder is included in Table 2. The difference in the percent of the cost of treatment attributed to labor between disorders is likely the result of different treatment methods for different disorders. Traditional infectious foot disorder treatments often involve cleaning and topical application of antibiotics in a foot wrap, whereas noninfectious lesions involve trimming and blocking the hoof to reduce weight bearing on the affected claw (Andrews et al., 2008). Some paper survey respondents wrote comments about the cost per block or per wrap used. Mean wrap price was $\$ 3.92 \pm 1.71(\mathrm{n}=13)$ and mean block price was $\$ 16.00 \pm 6.15(\mathrm{n}=18)$. Therefore, it is not surprising that we found a greater percentage of treatment costs attributed to labor for infectious disorders and a greater percentage of treatment costs attribute to supplies for noninfectious disorders.

Region, herd size served, and trimming frequency did not influence the percent of total treatment costs attributed to labor or supplies for digital dermatitis, sole ulcers, thin soles, toe ulcers, or white line disease $(P>$ 0.05). The percent of the total treatment costs of foot rot attributed to supplies did not differ by region, herd size served, or trimming frequency, but the percent of the total treatment cost of foot rot attributed to labor differed by region $(P=0.03, \mathrm{n}=81)$. For unknown reasons, hoof trimmers from the Midwest attributed more of the foot rot costs to labor $(75.6 \pm 4.2 \%)$ than hoof trimmers from the Northeast $(60.6 \pm 4.2 \%)$.

\section{Rank Order Responses}

Foot Disorder Total Costs. Respondents were asked to rank the selected foot disorders based on the total cost per case to the producer (treatment and labor costs plus the reduction in milk yield, reduced reproductive performance, and so on) from most expensive (1) to least expensive (6). The frequency of responses is reported in Table 3. Hoof trimmer respondents most often ranked digital dermatitis total cost per case to the producer as greatest. Conversely, multiple previously published economic estimates of foot disorder costs agree that sole ulcers are the most expensive foot disorder per case, whereas infectious conditions, including digital dermatitis and foot rot, tend to be the least expensive per case (Willshire and Bell, 2009; Cha et al., 2010; Charfeddine and Pérez-Cabal, 2017). The survey question about the cost ranking of different foot disorders tried to emphasize the cost per case component, but the ranking of digital dermatitis total costs per case as first by hoof trimmers could indicate that some respondents focused more on the total cost to the herd. This is especially possible given that respondents reported charging producers more to treat either sole ulcers or white line disease than digital dermatitis (Table 2).

Interestingly, among hoof trimmer respondents that did not rank the total cost per case of digital dermatitis as first, most ranked the total cost per case of digital dermatitis as last. This indicates that some of the respondents likely did consider the per-case portion of the question more seriously than others. Thin soles were most commonly ranked as the lowest cost 
Table 3. Ranking frequency (\%) of the estimated total cost per case to the producer (treatment and labor costs plus the reduction in milk yield, reduced reproductive performance, and so on) of selected foot disorders as evaluated by a survey of hoof trimmers [ranking from most expensive (1) to least expensive (6)]

\begin{tabular}{|c|c|c|c|c|c|c|c|}
\hline \multirow[b]{2}{*}{ Foot disorder } & \multirow[b]{2}{*}{$\mathrm{n}$} & \multicolumn{6}{|c|}{ Rank } \\
\hline & & 1 & 2 & 3 & 4 & 5 & 6 \\
\hline Digital dermatitis & 112 & 33.9 & 9.8 & 4.5 & 9.8 & 13.4 & 28.6 \\
\hline Toe ulcer & 109 & 22.9 & 19.3 & 15.6 & 19.3 & 12.8 & 10.1 \\
\hline Foot rot & 111 & 19.8 & 11.7 & 9.9 & 20.7 & 19.8 & 18.0 \\
\hline Sole ulcer & 111 & 11.7 & 27.0 & 26.1 & 17.1 & 13.5 & 4.5 \\
\hline White line disease & 112 & 7.1 & 23.2 & 30.4 & 20.5 & 8.9 & 9.8 \\
\hline Thin sole & 111 & 6.3 & 7.2 & 13.5 & 12.6 & 30.6 & 29.7 \\
\hline
\end{tabular}

per case to the producer. No previous foot disorder cost estimate studies have included either toe ulcers or thin soles; rarely have epidemiological studies included these conditions. Therefore, it is unclear if ranking of thin soles as having the least total cost per case is consistent with reality or not; more research on the effects of this condition on cow performance is needed.

Lameness Reduction Benefits. Respondents were asked to rank selected potential benefits of reducing lameness from most important (1) to least important (8). The frequency of responses is reported in Table 4. Among hoof trimmers, enhanced animal welfare and increased milk production were the most important benefits identified. Dolecheck and Bewley (2018) summarized that the top contributing categories to the total cost of lameness have traditionally been calculated as increased culling and death, reduced reproductive performance, and decreased milk yield. However, no previous literature has considered the costs of lameness attributed to negative animal welfare, excluding it from consideration in Dolecheck and Bewley (2018). In agreement with respondents to this survey, recent studies have highlighted the connection between animal welfare and lameness (von Keyserlingk et al., 2009; Barkema et al., 2015).

Reduced veterinary and hoof trimmer fees were ranked as the least important potential benefit associated with reducing lameness. This was in agree- ment with Dolecheck and Bewley (2018), who found that previous total cost of lameness estimates have ranked reduced drug and supply costs, reduced outside labor, and reduced producer labor as less important cost categories. The second least important response was decreased incidence of other diseases. Evidence of the connection between lameness and other diseases is mixed (Dolecheck and Bewley, 2018). Because of the number of options included in this rank order question, the most valuable insight comes from those options ranked highest and lowest, whereas the options in the middle are less interpretable. Overall, respondents' answers indicated that hoof trimmers have a good understanding of the contribution of different cost categories to the total cost of lameness as defined in currently available literature. However, the voluntary survey strategy may have selected for hoof trimmers who are more interested in research and up-to-date on published literature, potentially influencing rank order responses.

\section{CONCLUSIONS}

The goal of our study was to collect information on foot disorder treatment costs charged by hoof trimmers and veterinarians to dairy producers. Low responses rates from veterinarians limited our study to hoof trimmer opinions only. Hoof trimmers reported that foot

Table 4. Ranking frequency (\%) of the potential benefits to producers of reducing dairy cow lameness as evaluated by a survey of hoof trimmers [ranking from most important (1) to least important (8)]

\begin{tabular}{|c|c|c|c|c|c|c|c|c|c|}
\hline Potential benefit & $\mathrm{n}$ & \multicolumn{8}{|c|}{ Rank } \\
\hline Enhanced animal welfare & 106 & 36.8 & 12.3 & 13.2 & 17.9 & 6.6 & 4.7 & 2.8 & 5.7 \\
\hline Increased cow longevity & 106 & 20.8 & 21.7 & 22.6 & 15.1 & 13.2 & 5.7 & 0.0 & 0.9 \\
\hline Reduced veterinary and hoof trimmer fees & 103 & 4.9 & 1.0 & 2.9 & 8.7 & 14.6 & 17.5 & 21.4 & 29.1 \\
\hline Decreased incidence of other diseases (not lameness) & 105 & 2.9 & 7.6 & 7.6 & 11.4 & 20.0 & 13.3 & 11.4 & 25.7 \\
\hline Reduced producer labor costs & 106 & 0.0 & 3.8 & 3.8 & 6.6 & 14.2 & 18.9 & 34.9 & 17.9 \\
\hline
\end{tabular}


disorder treatment cost per case was greatest for toe ulcers, followed by sole ulcers, white line disease, thin sole, foot rot, and digital dermatitis. Additional insight was provided into hoof trimmers' general billing practices and views on the prevalence and total cost per case of different foot disorders and the value of their prevention. Minimal effects of region, herd size served, or trimming frequency were found on responses. The treatment cost estimates found in this study can aid in improving economic estimates of the total cost per case of different foot disorders. More accurate foot disorder total cost per case estimates could help improve decisions regarding the treatment of individual foot disorder cases and the adoption of foot disorder prevention strategies.

\section{ACKNOWLEDGMENTS}

The authors thank all survey respondents, along with the Hoof Trimmers Association (Missoula, MT) and the American Association of Bovine Practitioners (Ashland, OH) for their help distributing the survey. Funding for this study was provided by Elanco Animal Health (Greenfield, IN).

\section{REFERENCES}

Adams, A. E., J. Lombard, C. Fossler, I. Román-Muñiz, and C. Kopral. 2017. Associations between housing and management practices and the prevalence of lameness, hock lesions, and thin cows on US dairy operations. J. Dairy Sci. 100:2119-2136.

Amory, J. R., Z. Barker, J. L. Wright, S. Mason, R. Blowey, and L. E. Green. 2008. Associations between sole ulcer, white line disease and digital dermatitis and the milk yield of 1824 dairy cows on 30 dairy cow farms in England and Wales from February 2003-November 2004. Prev. Vet. Med. 83:381-391.

Andrews, A. H., R. Blowey, H. Boyd, and R. Eddy. 2008. Bovine Medicine: Diseases and Husbandry of Cattle. John Wiley \& Sons, Hoboken, NJ.

Barkema, H. W., M. A. G. von Keyserlingk, J. P. Kastelic, T. J. G. M. Lam, C. Luby, J. P. Roy, S. J. LeBlanc, G. P. Keefe, and D. F. Kelton. 2015. Invited review: Changes in the dairy industry affecting dairy cattle health and welfare. J. Dairy Sci. 98:7426-7445.

Bicalho, R. C., S. Cheong, G. Cramer, and C. Guard. 2007. Association between a visual and an automated locomotion score in lactating Holstein cows. J. Dairy Sci. 90:3294-3300.
Bruijnis, M. R., H. Hogeveen, and E. Stassen. 2010. Assessing economic consequences of foot disorders in dairy cattle using a dynamic stochastic simulation model. J. Dairy Sci. 93:2419-2432.

Cha, E., J. Hertl, D. Bar, and Y. Gröhn. 2010. The cost of different types of lameness in dairy cows calculated by dynamic programming. Prev. Vet. Med. 97:1-8.

Charfeddine, N., and M. A. Pérez-Cabal. 2017. Effect of claw disorders on milk production, fertility, and longevity, and their economic impact in Spanish Holstein cows. J. Dairy Sci. 100:653-665.

Cook, N. B., and K. V. Nordlund. 2009. The influence of the environment on dairy cow behavior, claw health and herd lameness dynamics. Vet. J. 179:360-369.

DeFrain, J. M., M. Socha, and D. Tomlinson. 2013. Analysis of foot health records from 17 confinement dairies. J. Dairy Sci. 96:73297339 .

Dolecheck, K. A., and J. M. Bewley. 2018. Animal board invited review: Dairy cow lameness expenditures, losses, and total cost. Animal 12:1462-1474. https://doi.org/10.1017/S1751731118000575.

Gernand, E., P. Rehbein, U. Von Borstel, and S. König. 2012. Incidences of and genetic parameters for mastitis, claw disorders, and common health traits recorded in dairy cattle contract herds. J. Dairy Sci. 95:2144-2156.

Guard, C. 2008. The costs of common diseases of dairy cattle. Pages 695-700 in Proceedings of the California Veterinary Conference. Advanstar Communications, Lenexa, KS.

Kleinhenz, K., P. Plummer, J. Danielson, R. G. Burzette, P. J. Gorden, J. Coetzee, J. A. Schleining, V. Cooper, B. Leuschen, and A. Krull. 2014. Survey of veterinarians and hoof trimmers on methods applied to treat claw lesions in dairy cattle. Bov. Pract. 48:47-52.

NAHMS. 2014. Dairy Cattle Management Practices in the United States. USDA-APHIS-VS, ed. National Animal Health Monitoring System, Fort Collins, CO.

Sanders, A. H., J. Shearer, and A. De Vries. 2009. Seasonal incidence of lameness and risk factors associated with thin soles, white line disease, ulcers, and sole punctures in dairy cattle. J. Dairy Sci. 92:3165-3174.

USDA. 2017. Dairy Data: Milk cows and production by state and region (Annual). Accessed Oct. 16, 2017. https://www.ers.usda.gov/ data-products/dairy-data.aspx.

Van Nuffel, A., I. Zwertvaegher, L. Pluym, S. Van Weyenberg, V. M. Thorup, M. Pastell, B. Sonck, and W. Saeys. 2015. Lameness detection in dairy cows: Part 1 . How to distinguish between non-lame and lame cows based on differences in locomotion or behavior. Animals (Basel) 5:838-860.

von Keyserlingk, M. A., J. Rushen, A. M. de Passillé, and D. M. Weary. 2009. Invited review: The welfare of dairy cattle-Key concepts and the role of science. J. Dairy Sci. 92:4101-4111.

Willshire, J., and N. Bell. 2009. An economic review of cattle lameness. Cattle Pract. 17:136-141.

Zinpro. 2014. Cattle Lameness Claw Lesions: Identify, Prevent, Control. Zinpro Corporation, Eden Prairie, MN. 
APPENDIX

Table A1. Veterinarian responses to a survey regarding dairy foot disorder prevalence, time to treat, treatment costs, and the percentage of treatment costs attributed to labor or supplies

\begin{tabular}{|c|c|c|}
\hline Foot disorder & $\begin{array}{l}\text { Number of } \\
\text { responses }\end{array}$ & $\begin{array}{c}\text { Response } \\
(\text { mean } \pm \mathrm{SD})\end{array}$ \\
\hline \multicolumn{3}{|l|}{ Digital dermatitis } \\
\hline$\%$ of all foot disorders & 16 & $24.7 \pm 12.7$ \\
\hline Time to treat $(\min )$ & 12 & $11.4 \pm 6.8$ \\
\hline Total charged (\$/case) & 12 & $46.3 \pm 26.5$ \\
\hline$\%$ attributed to labor & 12 & $75.6 \pm 16.7$ \\
\hline$\%$ attributed to supplies & 12 & $24.4 \pm 16.7$ \\
\hline \multicolumn{3}{|l|}{ Foot rot } \\
\hline$\%$ of all foot disorders & 16 & $17.0 \pm 10.4$ \\
\hline Time to treat $(\min )$ & 12 & $11.4 \pm 6.1$ \\
\hline Total charged (\$/case) & 12 & $65.1 \pm 38.1$ \\
\hline$\%$ attributed to labor & 12 & $57.5 \pm 23.6$ \\
\hline$\%$ attributed to supplies & 12 & $42.5 \pm 23.6$ \\
\hline \multicolumn{3}{|l|}{ Sole ulcer } \\
\hline$\%$ of all foot disorders & 16 & $27.4 \pm 14.3$ \\
\hline Time to treat $(\min )$ & 12 & $21.3 \pm 10.1$ \\
\hline Total charged (\$/case) & 12 & $69.8 \pm 30.8$ \\
\hline$\%$ attributed to labor & 12 & $73.4 \pm 18.3$ \\
\hline$\%$ attributed to supplies & 11 & $26.6 \pm 18.3$ \\
\hline \multicolumn{3}{|l|}{ Thin sole } \\
\hline$\%$ of all foot disorders & 16 & $3.3 \pm 5.0$ \\
\hline Time to treat $(\min )$ & 12 & $9.6 \pm 6.2$ \\
\hline Total charged (\$/case) & 10 & $53.1 \pm 35.8$ \\
\hline$\%$ attributed to labor & 12 & $64.8 \pm 37.1$ \\
\hline$\%$ attributed to supplies & 12 & $18.5 \pm 23.1$ \\
\hline \multicolumn{3}{|l|}{ Toe ulcer } \\
\hline$\%$ of all foot disorders & 16 & $2.8 \pm 3.0$ \\
\hline Time to treat $(\mathrm{min})$ & 12 & $16.9 \pm 8.0$ \\
\hline Total charged (\$/case) & 11 & $78.2 \pm 48.9$ \\
\hline$\%$ attributed to labor & 12 & $66.7 \pm 27.1$ \\
\hline$\%$ attributed to supplies & 12 & $25.0 \pm 18.8$ \\
\hline \multicolumn{3}{|l|}{ White line disease } \\
\hline$\%$ of all foot disorders & 16 & $18.3 \pm 14.8$ \\
\hline Time to treat (min) & 12 & $18.8 \pm 7.6$ \\
\hline Total charged (\$/case) & 12 & $65.3 \pm 33.6$ \\
\hline$\%$ attributed to labor & 12 & $77.1 \pm 17.2$ \\
\hline$\%$ attributed to supplies & 12 & $22.9 \pm 17.2$ \\
\hline \multicolumn{3}{|l|}{ Other lameness } \\
\hline$\%$ of all foot disorders & 16 & $6.6 \pm 6.7$ \\
\hline
\end{tabular}


Table A2. Ranking frequency (\%) of the estimated total cost per case to the producer (treatment and labor costs plus the reduction in milk yield, reduced reproductive performance, and so on) of selected foot disorders as evaluated by a survey of veterinarians [ranking was most expensive (1) to least expensive (6)]

\begin{tabular}{|c|c|c|c|c|c|c|c|}
\hline \multirow[b]{2}{*}{ Foot disorders } & \multirow[b]{2}{*}{$\mathrm{n}$} & \multicolumn{6}{|c|}{ Rank } \\
\hline & & 1 & 2 & 3 & 4 & 5 & 6 \\
\hline Sole ulcer & 16 & 31.3 & 31.3 & 6.3 & 18.8 & 12.5 & 0.0 \\
\hline Digital dermatitis & 16 & 25.0 & 37.5 & 25.0 & 6.3 & 0.0 & 6.3 \\
\hline Foot rot & 16 & 18.8 & 0.0 & 43.8 & 12.5 & 12.5 & 12.5 \\
\hline Toe ulcer & 16 & 12.5 & 12.5 & 0.0 & 25.0 & 18.8 & 31.3 \\
\hline White line disease & 16 & 6.3 & 18.8 & 18.8 & 25.0 & 18.8 & 12.5 \\
\hline Thin sole & 16 & 6.3 & 0.0 & 6.3 & 12.5 & 37.5 & 37.5 \\
\hline
\end{tabular}

Table A3. Ranking frequency (\%) of the potential benefits to producers of reducing dairy cow lameness as evaluated by a survey of veterinarians [ranking was from most important (1) to least important (8)]

\begin{tabular}{|c|c|c|c|c|c|c|c|c|c|}
\hline Potential benefit & $\mathrm{n}$ & \multicolumn{8}{|c|}{ Rank } \\
\hline Enhanced animal welfare & 16 & 50.0 & 18.8 & 6.3 & 6.3 & 6.3 & 0.0 & 0.0 & 12.5 \\
\hline Increased cow longevity & 16 & 12.5 & 25.0 & 6.3 & 18.8 & 31.3 & 63.0 & 0.0 & 0.0 \\
\hline Increased reproductive performance & 16 & 0.0 & 18.8 & 37.5 & 37.5 & 6.3 & 0.0 & 0.0 & 0.0 \\
\hline Decreased incidence of other diseases (not lameness) & 16 & 0.0 & 6.3 & 18.8 & 18.8 & 31.3 & 18.8 & 6.3 & 0.0 \\
\hline Reduced producer labor costs & 16 & 0.0 & 0.0 & 0.0 & 12.5 & 0.0 & 0.0 & 56.3 & 31.3 \\
\hline
\end{tabular}




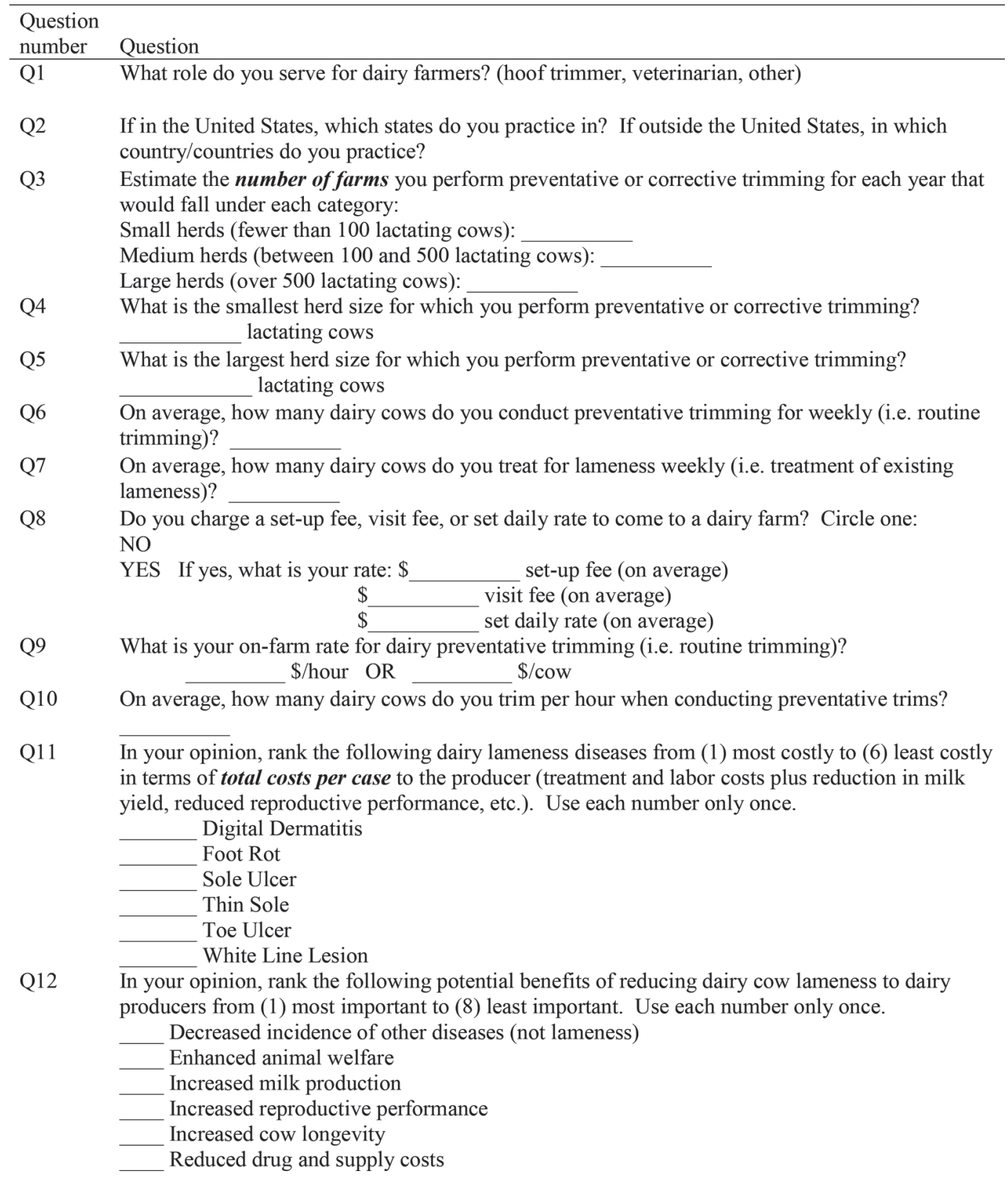

Figure A1. Questions included in a survey of hoof trimmers and veterinarians aimed at collecting and summarizing information on foot disorder treatment costs. 
Reduced producer labor costs

Reduced veterinary/hoof trimmer fees

Q13 Of all dairy cow lameness cases that you have treated in the past 12 months, what is your best estimate of the percent that would fall under each of the following classifications (the total should equal $100 \%$ ).

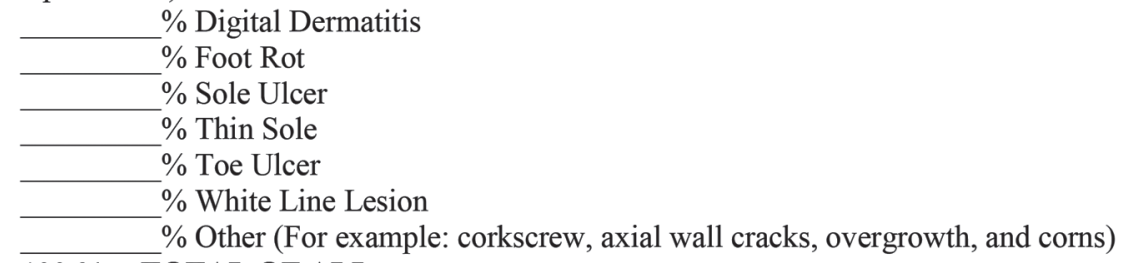

Q14 Approximately how much time do you spend per hoof to treat a case of:

Digital Dermatitis: minutes

Foot Rot:

Sole Ulcer:

Thin Sole:

minutes

Toe Ulcer:

White Line Lesion:

minutes

minutes

minutes

Q15 Do you generally recommend milk withholding following treatment of each of the following diseases (mark "Yes" or "No")? If "Yes", indicate for how many days milk withholding is recommended:

\begin{tabular}{|l|l|l|l|}
\hline Disease & No & Yes & $\begin{array}{c}\text { If yes, days withhold is recommended } \\
\text { after treatment: }\end{array}$ \\
\hline $\begin{array}{l}\text { Digital } \\
\text { Dermatitis }\end{array}$ & & & \\
\hline Foot Rot & & & \\
\hline Sole Ulcer & & & \\
\hline Thin Sole & & & \\
\hline Toe Ulcer & & & \\
\hline $\begin{array}{l}\text { White Line } \\
\text { Lesion }\end{array}$ & & & \\
\hline
\end{tabular}

Q16 In the first blank column, list how much you charge a dairy producer to treat one case of each of the diseases listed.

Then indicate what percent of the total charge of each case is for labor vs. supplies. The total of "\% Labor" and "\% Supplies" for each row should equal 100\%.

\begin{tabular}{|l|c|c|c|c|}
\hline Disease & $\begin{array}{c}\text { Total amount } \\
\text { charged to the } \\
\text { producer } \\
\$\end{array}$ & $\begin{array}{c}\text { \% } \\
\text { Labor }\end{array}$ & $\begin{array}{c}\% \\
\text { Supplies }\end{array}$ & $\begin{array}{c}\text { Total } \\
\%\end{array}$ \\
\hline Digital Dermatitis & & & & $100 \%$ \\
\hline Foot Rot & & & & $100 \%$ \\
\hline Sole Ulcer & & & & $100 \%$ \\
\hline Thin Sole & & & & $100 \%$ \\
\hline Toe Ulcer & & & & $100 \%$ \\
\hline White Line Lesion & & & & $100 \%$ \\
\hline
\end{tabular}

Figure A1 (Continued). Questions included in a survey of hoof trimmers and veterinarians aimed at collecting and summarizing information on foot disorder treatment costs. 
Lesion Descriptions: For the remaining questions, please consider the below dairy lameness disease definitions and refer to the "Claw Zones" indicated in the figure:
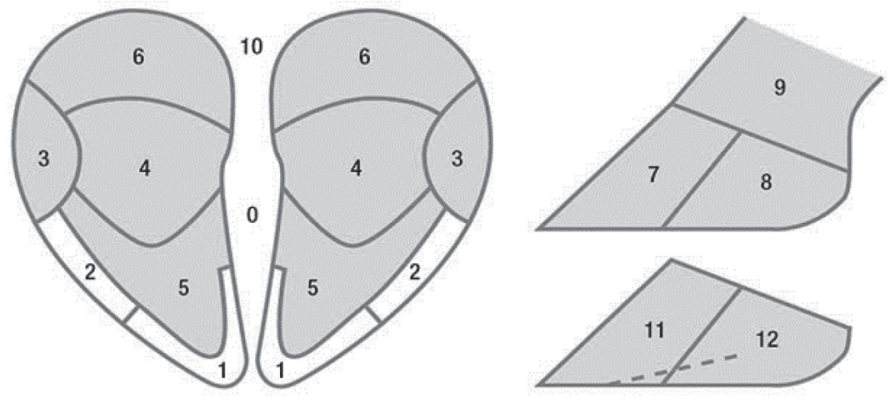

Digital Dermatitis (also called Hairy Heel Warts or Mortellaro Disease)

Claw Zones affected: any zones along the coronary band including zones 0,9 , and 10

Common signs include:

- Typically located at the end of the interdigital cleft

- Acute cases have bright-red lesions $>0.75$ inches $(2 \mathrm{~cm})$ that are painful and raw

- Chronic cases have lesions with lots of skin/hair around them, but are not painful

Foot Rot (also called Foot Foul, Interdigital Phlegmon, or Interdigital Necrobacillosis)

Claw Zones affected: 9

Common signs include:

- Symmetrical hard swelling of tissue above the claws (acute onset, "overnight")

- Can occur with dead, smelly skin between the claws

Sole ulcer (also called Pododermatitis Circumscripta, Rusterholz Disease)

Claw Zones affected: 4

Common signs include:

- Localized defect in sole horn that exposes corium

- Can also be a hemorrhage that is painful to hoof test

- Typically occurs on the inner side of the sole on the outer claw, but can occur in the heel

Thin Sole

Claw Zones affected: 4, 5

Common signs include:

- Sole moves when thumb pressure is applied at the toe

Toe Ulcer

- Dorsal wall length is $<3$ inches $(7.5 \mathrm{~cm})$

Claw Zones affected: 1

Common signs include:

- Penetration or separation of the horn in the toe triangle that results in exposure or infection of the corium

White line lesion (also called White Line Separation or White Line Disease)

Claw Zones affected: 1, 2, 3

Common signs include:

- Separation of the white line, which may result in abscesses (pus filled cavity) in the white line region

- If severe this can be accompanied by swelling of the affected claw

Figure A2. Foot disorder definitions provided to respondents in a survey of hoof trimmers and veterinarians aimed at collecting and summarizing information on foot disorder treatment costs. 